\title{
Extracts of Scutellariae Radix inhibit low-density lipoprotein oxidation and the lipopolysaccharide-induced macrophage inflammatory response
}

\author{
OHN SOON KIM, CHANG-SEOB SEO, YEJI KIM, HYEUN-KYOO SHIN and HYEKYUNG HA
}

\begin{abstract}
Herbal Medicine Research Division, Korea Institute of Oriental Medicine, Yuseong-gu, Daejeon 305-811, Republic of Korea
\end{abstract}
Received June 5, 2014; Accepted February 24, 2015

DOI: $10.3892 / \mathrm{mmr} .2015 .3502$

\begin{abstract}
Traditional herbal formulas made from Scutellariae Radix (SR), the root of Scutellaria baicalensis, have previously been used in the treatment of inflammatory diseases, such as atherosclerosis. The aim of the present study was to investigate the effects of SR on low-density lipoprotein (LDL) oxidation and inflammation in macrophages, which are early events in the development of atherosclerosis. High-performance liquid chromatography photo-diode array analysis was used to obtain a three-dimensional chromatogram of SR. The antioxidative effects of SR were evaluated by determining its scavenging activities against ABTS and DPPH radicals. The inhibitory effect of SR on LDL oxidation was examined using a thiobarbituric acid-reactive substance assay and a relative electrophoretic mobility assay. In addition, the anti-inflammatory effects of SR were evaluated in lipopolysaccharide (LPS)-induced RAW264.7 murine macrophage cells. The results showed that SR exhibited radical-scavenging activities in a dose-dependent manner; in addition, SR attenuated the $\mathrm{Cu}^{2+}$-induced oxidation of LDL as well as significantly inhibited nitric oxide (NO) production and inducible NO synthase (iNOS) expression in LPS-induced RAW264.7 cells. Furthermore, SR induced the protein expression of heme oxygenase-1 (HO-1) in RAW264.7 cells. In conclusion, the results of the present study demonstrated that SR decreased the oxidation of LDL and suppressed inflammatory responses in macrophages, which occurred at least in part via the induction of HO-1. These results therefore suggested that SR may be a potential therapeutic agent for the treatment of atherosclerosis.
\end{abstract}

Correspondence to: Dr Hyekyung Ha, Herbal Medicine Research Division, Korea Institute of Oriental Medicine, 1672 Yuseongdae-ro, Yuseong-gu, Daejeon 305-811, Republic of Korea

E-mail: hkha@kiom.re.kr

Key words: Scutellariae radix, low-density lipoprotein oxidation, inflammation, atherosclerosis

\section{Introduction}

Atherosclerosis is a complex vascular disorder involved in the pathogenesis of myocardial and cerebral infarction (1). The atherosclerotic process involves low-density lipoprotein (LDL) oxidation, oxidized LDL (oxLDL) uptake and inflammatory response induction in macrophages, the transformation of the lipid-laden macrophages into foam cells, proliferation of vascular smooth muscle cells (VSMCs) as well as foam cell accumulation resulting in fatty streaks and subsequent plaque formation $(2,3)$. Modulation of these key atherogenic events may therefore be a promising therapeutic strategy for atherosclerotic management.

Scutellariae Radix (SR), the root of Scutellaria baicalensis, is one of the most widely used types of Traditional Chinese Herbal Medicines. SR, whose Chinese name is Huang-qin, forms the major ingredient of numerous herbal preparations and is used to treat bacterial infections as well as various inflammatory diseases. The principal constituents of SR contain diverse flavonoids, such as baicalein, baicalin and wogonin (4). In addition, previous studies have demonstrated that SR may have various beneficial pharmacological activities including antioxidative (5), anticancer $(6,7)$ and anti-inflammatory $(8,9)$ effects.

Heme oxygenase $(\mathrm{HO})$, a rate-limiting enzyme in heme degradation (10), is an inducible form of $\mathrm{HO}$, which was reported to have cytoprotective effects (11). These effects include pro-oxidative heme degradation, which results in biliverdin release and the subsequent conversion of biliverdin into bilirubin, both of which have antioxidant properties (12). In addition, heme degradation generates carbon monoxide, which has antiproliferative and anti-inflammatory properties $(13,14)$. Numerous studies have suggested that HO-1 may be a potential therapeutic target for the treatment of inflammatory diseases, such as atherosclerosis.

In the present study, high-performance liquid chromatography (HPLC) was used to analyze the flavonoid components of SR. In addition, the present study investigated whether SR exhibited inhibitory effects on LDL oxidation and the macrophage inflammatory response, which are early events in the development of atherosclerosis.

\section{Materials and methods}

Preparations of SR extract, standard and sample solution. The roots of S. baicalensis were purchased in April 2012 
from Kwangmyungdang Medicinal Herbs (Ulsan, Korea) and were confirmed taxonomically by Professor Je-Hyun Lee of Dongkuk University (Gyeongju, Korea). A voucher specimen of SR (SR-2012-EBM91) was deposited at the Herbal Medicine Formulation Research Group, Korea Institute of Oriental Medicine (Daejeon, Korea). Dried roots of $S$. baicalensis were extracted using distilled water (1 liter) through reflux at $100^{\circ} \mathrm{C}$ for $2 \mathrm{~h}$. The extracted solution was filtered through filter paper, evaporated to dryness and then freeze-dried (47.84 g). The yield of water extract obtained was $47.84 \%$. For HPLC analysis, the $100 \mathrm{mg}$ sample powder was dissolved in $100 \mathrm{ml} 70 \%$ methanol (J.T. Baker, Phillipsburg, NJ, USA) and the solution was passed through a $0.2 \mathrm{~mm}$ syringe filter (Woongki Science Co. Ltd, Seoul, Korea) prior to HPLC injection. Baicalin, baicalein and wogonin were purchased from Wako Pure Chemical Industries, Ltd (Osaka, Japan). The purities of these compounds were $>98.0 \%$, as determined using HPLC analysis. Standard stock solutions of baicalin, baicalein and wogonin (all 1,000 $\mu \mathrm{g} / \mathrm{ml}$ ) were prepared in $100 \%$ methanol and stored at $4^{\circ} \mathrm{C}$. Working standard solutions were prepared by serial dilution of $3.91-500 \mu \mathrm{g} / \mathrm{ml}$ baicalin, 2.34-300 $\mu \mathrm{g} / \mathrm{ml}$ baicalein, and $1.53-200.00 \mu \mathrm{g} / \mathrm{ml}$ wogonin, with $100 \%$ methanol.

Chromatographic system. Analysis was performed using a Shimadzu LC-10A HPLC system (Shimadzu Corp., Kyoto, Japan), which was comprised of a solvent delivery unit, an online degasser, an autosampler and a photo-diode array (PDA) detector. The data processor used LCsolution software (version 1.24; Shimadzu Corp.). The analytical column used was a Gemini C18 (250x4.6 mm; particle size, $5 \mathrm{~mm}$; Phenomenex, Inc., Torrance, CA, USA). The mobile phases were (A) $1.0 \%$ acetic acid (Merck KGaA, Darmstadt, Germany) in aqueous solution and (B) $1.0 \%$ acetic acid in acetonitrile-methanol (7:3; J.T. Baker) solution. Gradient elution of the two mobile phases were as follows: $25 \% \mathrm{~B}$ for 0-10 $\mathrm{min}, 25-45 \% \mathrm{~B}$ for $10-20 \mathrm{~min}, 45 \% \mathrm{~B}$ for $20-24 \mathrm{~min}$, 45-48\% B for 24-35 min, 48-25\% B for 35-40 min and $25 \% \mathrm{~B}$ for $40-50 \mathrm{~min}$. Analysis was performed at a flow rate of $1.0 \mathrm{ml} / \mathrm{min}$ with PDA detection at $277 \mathrm{~nm}$. The injection volume was $10 \mu 1$.

Determination of antioxidant activity. The radical-scavenging activity of SR against 2,2'-azino-bis (3-ethylbenzothiazoline-6-sulfonic acid) diammonium salt (ABTS; Sigma-Aldrich, St. Louis, MO, USA) was determined using the method described by Re et al (15), with slight modifications. In brief, ABTS radical cations $\left(\mathrm{ABTS}^{+}\right)$were produced by reacting $7 \mathrm{mM}$ ABTS solution with $2.45 \mathrm{mM}$ potassium persulfate (Sigma-Aldrich); the solution was stored in the dark at room temperature for $16 \mathrm{~h}$. The solution was then diluted with phosphate-buffered saline (PBS; pH 7.4; Bio-Rad Laboratories, Inc., Hercules, CA, USA) to an absorbance of 0.7 at $734 \mathrm{~nm}$ using a microplate reader (Benchmark Plus; Bio-Rad Laboratories, Inc.). A total of $100 \mathrm{ml}$ diluted $\mathrm{ABTS}^{+}$solution was then added to a 96-well plate containing the samples $(20,40,80$ and $160 \mathrm{mg} / \mathrm{ml} \mathrm{SR}$, or $2.5,5$ and $10 \mathrm{mg} / \mathrm{ml} \mathrm{AA}$ ). Following incubation for $5 \mathrm{~min}$, absorbance was measured at $734 \mathrm{~nm}$ using a Benchmark Plus microplate reader. The extent of decolorization was calculated as the percentage reduction in absorbance. The scavenging capacity of the test compounds was calculated using the following equation: ABTS radical-scavenging activity $=\left(1-\mathrm{A}_{\text {sample }} / \mathrm{A}_{\text {control }}\right) \times 100$, where $\mathrm{A}_{\text {control }}$ is the absorbance of the negative control and $\mathrm{A}_{\text {sample }}$ is the absorbance of the standard antioxidant or extract. $\mathrm{RC}_{50}$ values (the concentration required for $50 \%$ reduction of ABTS radical) were calculated as the concentration at which the absorbance was diminished by $50 \%$.

The 2,2-diphenyl-2-picrylhydrazyl (DPPH; Sigma-Aldrich) free radical-scavenging activity of SR was determined according to the method described by Moreno et al (16), with certain modifications. In brief, $100 \mu 1$ sample at various concentrations $(20,40,80$ and $160 \mathrm{mg} / \mathrm{ml} \mathrm{SR}$, or 5,10 and $20 \mathrm{mg} / \mathrm{ml} \mathrm{AA})$ was added to $100 \mu \mathrm{l} \mathrm{DPPH}$ solution $(0.15 \mathrm{mM}$ in ethanol) in a 96-well plate. Following incubation for $30 \mathrm{~min}$ in the dark at room temperature, the absorbance was measured at $517 \mathrm{~nm}$. The scavenging activity (\%) was calculated using the formula described in the preceding paragraph. Ascorbic acid (AA), a positive control for the antioxidant assay, was purchased from Sigma-Aldrich.

$\mathrm{CuSO}_{4}$-mediated $\mathrm{LDL}$ oxidation. $\mathrm{A} \mathrm{CuSO}_{4}$-mediated method (17) was used to induce the oxidation of LDL. LDL samples (500 $\mu \mathrm{g}$ protein/ml; Biomedical Technologies, Inc., Stoughton, MA, USA) were prepared at $37^{\circ} \mathrm{C}$ for $5 \mathrm{~min}$ in a medium containing $10 \mathrm{mM}$ phosphate buffer $(\mathrm{pH} 7.4$; Sigma-Aldrich) with various sample concentrations. Oxidation was then initiated by the addition of $25 \mu \mathrm{M} \mathrm{CuSO}_{4}$ at $37^{\circ} \mathrm{C}$ for $6 \mathrm{~h}$. The oxidation, lipid peroxidation and electrophoretic mobility of the LDL were then measured using the thiobarbituric acid-reactive substance (TBARS) and relative electrophoretic mobility (REM) assays, as described below.

Determination of TBARS. Lipid peroxidation of LDL was estimated by measuring malondialdehyde (MDA) concentration using a TBARS assay kit (BioAssay Systems, Hayward, CA, USA) according to the manufacturer's instructions (18). In brief, following oxidation, $50 \mu \mathrm{g}$ LDL was mixed with $200 \mu \mathrm{l}$ thiobarbituric acid and incubated at $100^{\circ} \mathrm{C}$ for $30 \mathrm{~min}$. When the reaction was complete, the absorbance was measured at $535 \mathrm{~nm}$ using a Benchmark Plus microplate reader.

REM assay. The electrophoretic mobility of LDLs was measured using agarose gel electrophoresis $(0.8 \%$ agarose in Tris-acetate-EDTA buffer; Bio-Rad Laboratories, Inc.) and Coomassie brilliant blue R-250 (Bio-Rad Laboratories, Inc.) staining. Electrophoresis was performed at $100 \mathrm{~V}$ for $30 \mathrm{~min}$ (Wide Mini-Sub Cell GT systems; Bio-Rad Laboratory, Inc.). REM was defined as the ratio of the distance migrated from the origin by oxLDL versus that of native LDL (19).

Cell culture. A RAW264.7 murine macrophage cell line was purchased from the American Type Culture Collection (Manassas, VA, USA). Cells were incubated at $37^{\circ} \mathrm{C}$ in $5 \% \mathrm{CO}_{2}$ in Dulbecco's modified Eagle's medium (DMEM; Gibco-BRL, Grand Island, NY, USA) supplemented with $100 \mathrm{U} / \mathrm{ml}$ penicillin, $100 \mu \mathrm{g} / \mathrm{ml}$ streptomycin and $5.5 \%$ fetal bovine serum (Gibco-BRL). 


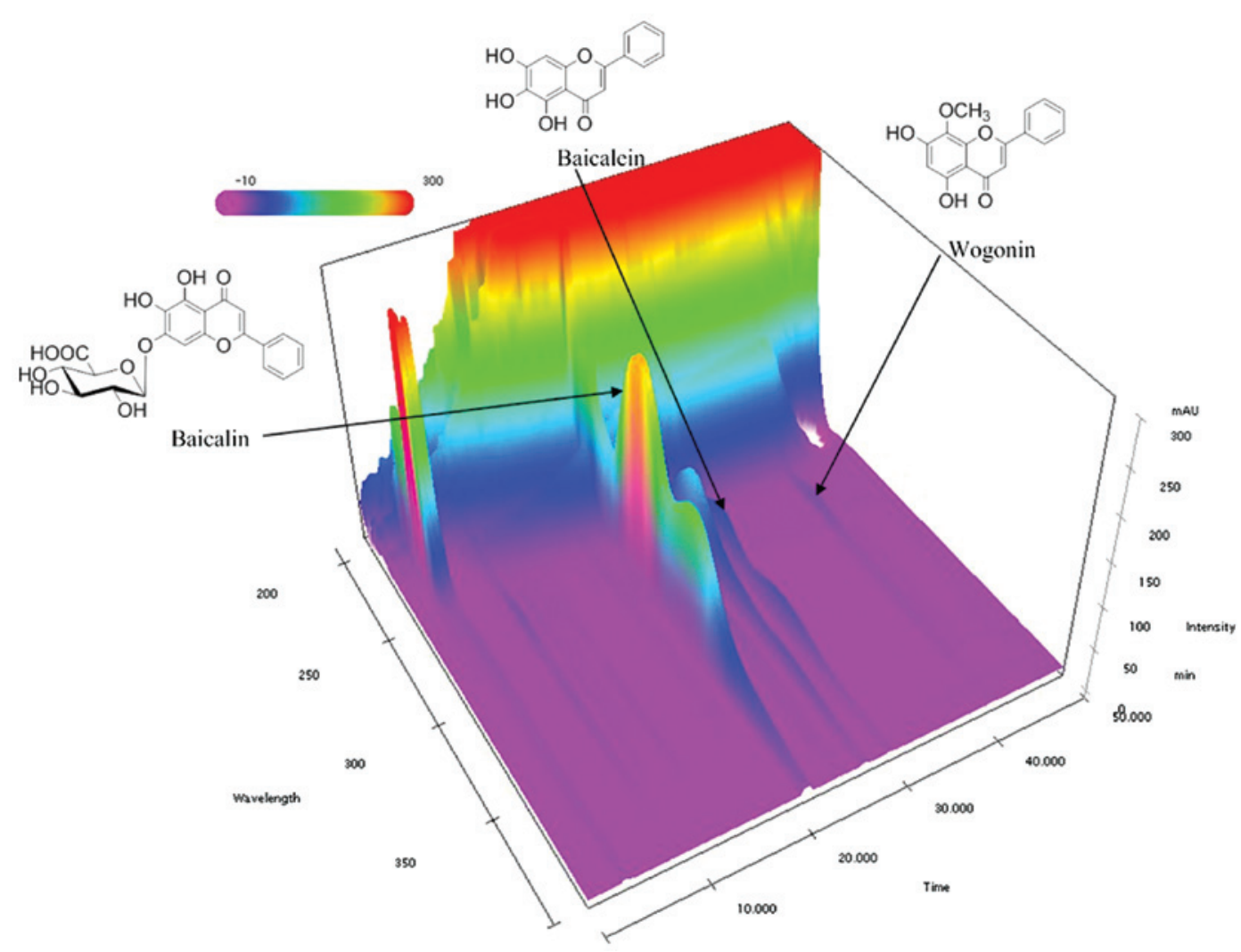

Figure 1. Three-dimensional chromatogram of SR extract. High-performance liquid chromatography photo-diode array analysis was used to produce a three-dimensional chromatogram in order to confirm and quantify the major components of SR extract (baicalin, baicalein and wogonin). SR, Scutellariae Radix.

In vitro cytotoxicity assay. Cells were seeded at $3 \times 10^{3}$ cells/well in a 96 -well plate and incubated with various concentrations of SR $(20,40,80$ and $160 \mu \mathrm{g} / \mathrm{ml})$ for $24 \mathrm{~h}$. CCK-8 solution (Dojindo Laboratories, Kumamoto, Japan) was added to cells, which were then incubated at $37^{\circ} \mathrm{C}$ for $4 \mathrm{~h}$. Following incubation, the absorbance was measured at $450 \mathrm{~nm}$ using a Benchmark Plus microplate reader.

Measurement of nitric oxide (NO) production. RAW264.7 cells were seeded at a density of $2.5 \times 10^{5}$ cells/well in a 48 -well plate and incubated with lipopolysaccharide (LPS; $1 \mu \mathrm{g} / \mathrm{ml}$; Sigma-Aldrich) for $24 \mathrm{~h}$ in the presence of various concentrations of SR $(20,40,80$ and $160 \mu \mathrm{g} / \mathrm{ml})$. $\mathrm{N}^{\mathrm{G}}$-Methyl-L-arginine acetate salt (NMMA), a positive control for the NO assay, was purchased from Sigma-Aldrich. Nitrite accumulated in the culture medium was quantified as an indicator of NO production. In brief, $50 \mu 1$ cell culture medium was mixed with $100 \mu \mathrm{l}$ Griess reagent (1\% sulfanilamide and $0.1 \%$ naphthylethylenediamine dihydrochloride in $2.5 \%$ phosphoric acid; Promega, Madison, WI, USA). The mixture was incubated at room temperature for $30 \mathrm{~min}$ and absorbance was then measured at $535 \mathrm{~nm}$ using a Benchmark Plus microplate reader. Fresh culture medium was used as a blank control for each experiment. The quantity of nitrite was determined from sodium nitrite standard curves produced in the present study.

Western blot analysis. Following treatment, as mentioned previously, the cells were washed twice with cold PBS and then lysed with 1X Laemmli lysis buffer [60 mM Tris-Cl (pH 6.8), $2 \%$ SDS, $10 \%$ glycerol and $0.01 \%$ bromophenol blue; Bio-Rad
Laboratories, Inc.] and boiled for $10 \mathrm{~min}$. The protein content was measured using a bicinchoninic acid protein assay reagent (Pierce Biotechnology, Inc., Rockford, IL, USA). Reducing agent (2-mercaptoethanol; Sigma-Aldrich) was added to the samples to obtain a final concentration of $355 \mathrm{mM}$ 2-mercaptoethanol. Equal quantities $(20 \mu \mathrm{g})$ of total cellular protein were resolved using 10\% SDS-polyacrylamide gel electrophoresis (Mini-Protean ${ }^{\circledR}$ Tetra Cell systems; Bio-Rad Laboratories, Inc.) and then transferred to a nitrocellulose membrane (Bio-Rad Laboratories, Inc.). The immunoblot was incubated with blocking solution (5\% skimmed milk; Bio-Rad Laboratories, Inc.) and then incubated overnight at $4{ }^{\circ} \mathrm{C}$ with the following primary antibodies: Anti- $\beta$-actin (1:1,000; cat. no. sc-81178; Santa Cruz Biotechnology, Inc. Dallas, TX, USA), anti-inducible NO synthase (iNOS; 1:1,000; cat. no. sc-7271; Santa Cruz Biotechnology, Inc.) and anti-HO-1 (1:1,000; cat. no. ab13248; Abcam, Boston, MA, USA). The blots were washed three times with Tris-buffered saline containing Tween 20 (TBST; Bio-Rad Laboratories, Inc.) and then incubated with a horseradish peroxidase-conjugated secondary antibody (1:5,000; cat. no. 115-035-003; Jackson ImmunoResearch, West Grove, PA, USA) for $60 \mathrm{~min}$ at room temperature. The blots were washed three times with TBST and then developed using an enhanced chemiluminescence kit (cat. no. RPN2232; Amersham, GE Healthcare, Arlington Heights, IL, USA). The bands were visualized using the ChemiDoc ${ }^{\mathrm{TM}}$ XRS Imaging system (Bio-Rad Laboratories, Inc.).

Statistical analysis. Data were analyzed using the one-way analysis of variance followed by the Dunnett's multiple 
Table I. Scavenging effects of SR on $\mathrm{ABTS}^{+}$.

\begin{tabular}{lccc}
\hline Agent & Concentration $(\mu \mathrm{g} / \mathrm{ml})$ & Scavenging effect $(\%)$ & $\mathrm{RC}_{50}(\mu \mathrm{g} / \mathrm{ml})$ \\
\hline SR & 20.0 & $23.95 \pm 2.31$ & $51.53 \pm 0.81$ \\
& 40.0 & $44.30 \pm 0.71$ & $70.70 \pm 1.94$ \\
AA & 16.0 & $95.43 \pm 0.82$ & $5.66 \pm 0.04$ \\
& 2.5 & $20.44 \pm 0.59$ & \\
& 5.0 & $44.39 \pm 1.26$ & \\
\hline
\end{tabular}

Values are presented as the mean \pm standard error of the mean of triplicate determinations. SR, Scutellariae Radix; ABTS ${ }^{+}, 2,2^{\prime}$-azino-bis (3-ethylbenzothiazoline-6-sulfonic acid) diammonium salt radical cations; $\mathrm{RC}_{50}$, concentration required for $50 \%$ reduction of $\mathrm{ABTS}^{+}$at $5 \mathrm{~min}$ reaction; AA, ascorbic acid.

Table II. Scavenging effects of SR on DPPH.

\begin{tabular}{lccc}
\hline Agent & Concentration $(\mu \mathrm{g} / \mathrm{ml})$ & Scavenging effect $(\%)$ & $\mathrm{RC}_{50}(\mu \mathrm{g} / \mathrm{ml})$ \\
\hline SR & 20.0 & $16.54 \pm 1.48$ & $63.07 \pm 3.00$ \\
& 40.0 & $37.70 \pm 1.87$ & \\
& 80.0 & $60.74 \pm 2.36$ & $8.56 \pm 0.04$ \\
AA & 160.0 & $78.68 \pm 1.64$ & \\
& 5.0 & $15.54 \pm 0.43$ & $63.66 \pm 0.25$ \\
\end{tabular}

Values are presented as the mean \pm standard error of the mean of triplicate determinations. SR, Scutellariae Radix; DPPH, 2,2-diphenyl-2-picrylhydrazyl; $\mathrm{RC}_{50}$, concentration required for $50 \%$ reduction of $\mathrm{DPPH}$ at $30 \mathrm{~min}$ reaction; $\mathrm{AA}$, ascorbic acid.

comparison tests using GraphPad InStat 3.05 software (GraphPad Software Inc., La Jolla, CA, USA). Values are presented as the mean \pm standard error of the mean. $\mathrm{P}<0.01$ and $\mathrm{P}<0.05$ were considered to indicate statistically significant differences between values.

\section{Results}

HPLC analysis. HPLC was used to confirm and quantify the standard components of SR, including baicalin, baicalein and wogonin. HPLC with a PDA detector were then used to produce a three-dimensional chromatogram (Fig. 1). Using optimized chromatography conditions, the three compounds were eluted in $<45$ min of sample analysis using the gradient elution of two mobile phases. The calibration curves of baicalin, baicalein and wogonin were: $y=37580.44 x+6967.22(3.91-500.00 \mu \mathrm{g} / \mathrm{ml})$, $y=55300.58 x-31507.13 \quad(2.34-300.00 \mu \mathrm{g} / \mathrm{ml})$ and $y=67938.69 x+11675.10(1.53-200.00 \mu \mathrm{g} / \mathrm{ml})$, respectively. The correlation coefficients of the three compounds were all 1.0000 . The content of baicalin, baicalein and wogonin in SR were: $110.16 \pm 0.41 \mathrm{mg} / \mathrm{g}, 14.04 \pm 0.11 \mathrm{mg} / \mathrm{g}$ and $3.90 \pm 0.05 \mathrm{mg} / \mathrm{g}$, respectively, with relative standard deviations of $<1.50 \%$.

Antioxidant activity of SR. In order to evaluate the antioxidant activity of SR, the scavenging activities of SR were tested against ABTS and DPPH radicals. The ABTS radical-scavenging activities of SR are presented in Table I. The results showed that the scavenging activities of SR increased in a dose-dependent manner. The $\mathrm{RC}_{50}$ against ABTS radicals was $51.53 \mu \mathrm{g} / \mathrm{ml}$, whereas the $\mathrm{RC}_{50}$ of ascorbic acid, as a positive control, was $5.66 \mu \mathrm{g} / \mathrm{ml}$. The antioxidant activities obtained using the DPPH method for SR are shown in Table II, the results of which were comparable to those of the ABTS assay. SR reduced the DPPH radical formation in a concentration-dependent manner. The $\mathrm{RC}_{50}$ of $\mathrm{SR}$ against DPPH radicals was $63.07 \mu \mathrm{g} / \mathrm{ml}$, whereas the $\mathrm{RC}_{50}$ of ascorbic acid was $8.56 \mu \mathrm{g} / \mathrm{ml}$.

Inhibitory effect of SR on $\mathrm{CuSO}_{4}$-mediated LDL oxidation. The degree of LDL oxidation and lipid peroxidation was evaluated using the TBARS assay to measure the concentration of the degradation byproduct MDA (20). As shown in Fig. 2A, $\mathrm{CuSO}_{4}$ increased the lipid peroxidation of LDL, which was then significantly inhibited following treatment with 80 or $160 \mu \mathrm{g} / \mathrm{ml}$ $\mathrm{SR}(\mathrm{P}<0.01)$. Alteration in agarose gel electrophoretic mobility reflects an increase in the negative charge of LDL particles, which occurs during oxidation (19). In the present study, oxidation of LDL performed in the presence of SR significantly attenuated the increase in electrophoretic mobility of oxLDL following $\mathrm{CuSO}_{4}$ treatment $(\mathrm{P}<0.01)$ (Fig. $2 \mathrm{~B}$ and $\left.\mathrm{C}\right)$. 
A

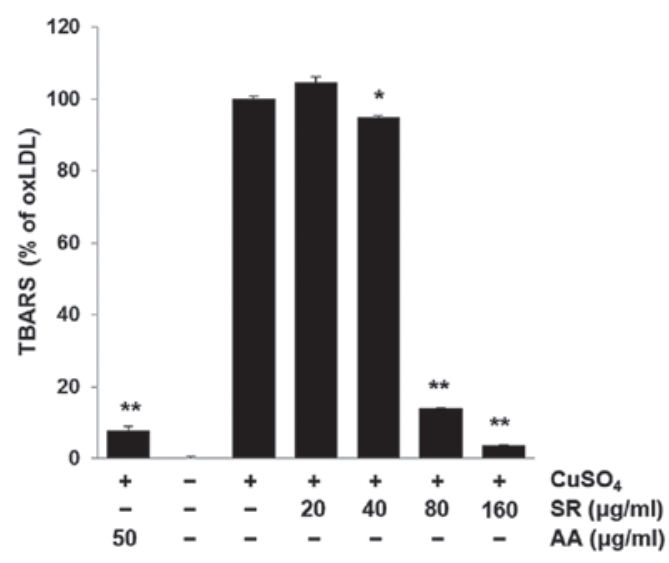

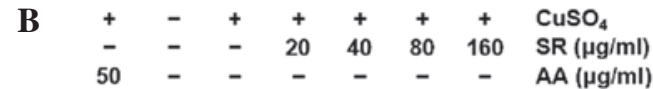

C

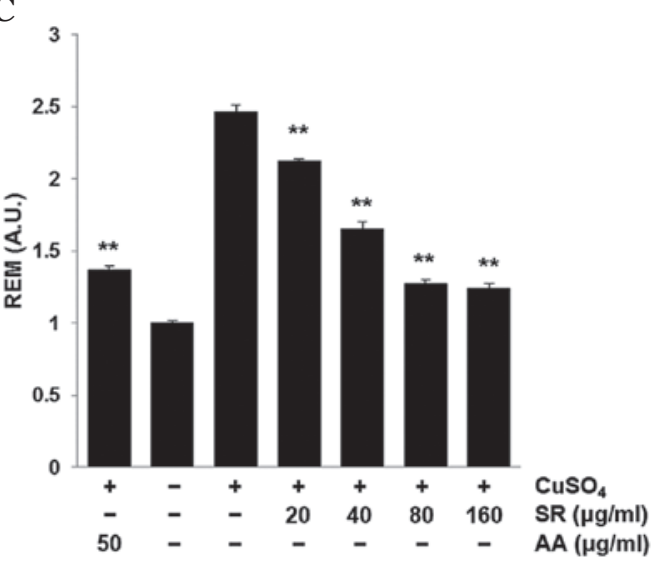

Figure 2. Effects of SR on $\mathrm{Cu}^{2+}$-induced LDL oxidation. SR (20,40,80 and $\left.160 \mu \mathrm{g} / \mathrm{ml}\right)$ or AA $(50 \mu \mathrm{g} / \mathrm{ml})$ in combination with LDL were incubated with $\mathrm{CuSO}_{4}$ for $6 \mathrm{~h}$ at $37^{\circ} \mathrm{C}$. (A) A TBARS assay was used to quantify the lipid peroxidation levels of LDL. (B and C) Representative gel and quantification of the electrophoretic mobility of oxLDL, as determined using an REM assay. Values are presented as the mean \pm standard error of the mean of triplicate experiments. "P<0.05 and ${ }^{* *} \mathrm{P}<0.01$ vs. oxLDL (CuSO ${ }_{4}$ only) group. SR, Scutellariae Radix; LDL, low-density lipoprotein; oxLDL, oxidized LDL; AA, ascorbic acid; TBARS, thiobarbituric acid-reactive substance; REM, relative electrophoretic mobility; A.U., absorbance units.

A

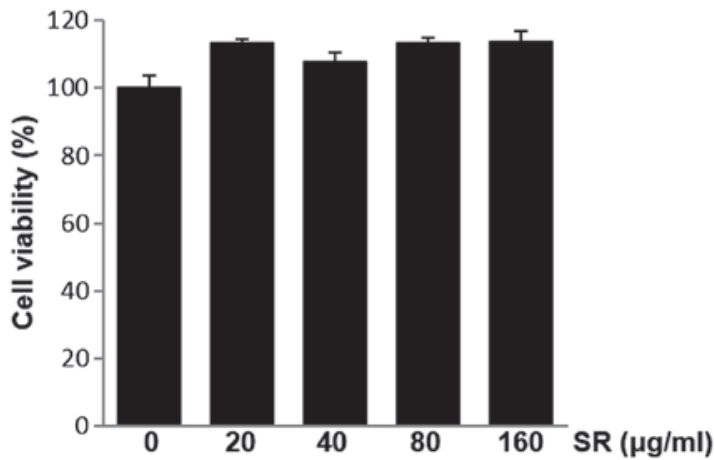

B

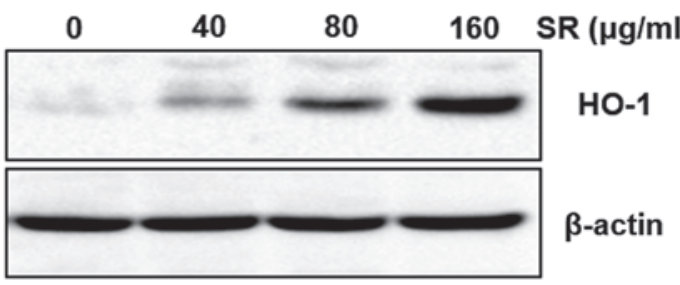

Figure 3. Effects of SR on viability and HO-1 expression in RAW264.7 cells. Cells were treated with SR (20, 40, 80 and $160 \mu \mathrm{g} / \mathrm{ml})$ for $24 \mathrm{~h}$. (A) A cell viability assay was performed using CCK-8 reagent. Values are presented as the mean \pm standard error of the mean of triplicate independent experiments. (B) Total cell lysates were prepared and the protein expression levels of HO-1 were determined using western blot analysis. $\beta$-actin was used as an internal control. SR, Scutellariae Radix; HO-1, heme oxygenase-1.

Cytotoxicity of SR in RAW264.7 cells. The cytotoxic effects of SR were investigated in RAW264.7 cells in order to establish the appropriate concentration range of SR treatment for subsequent experiments. The cytotoxicity of SR in this
A

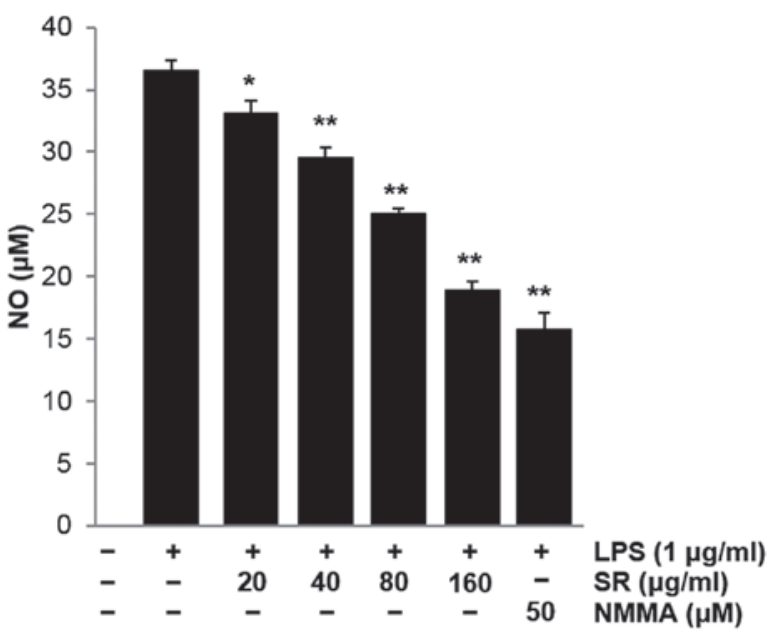

B

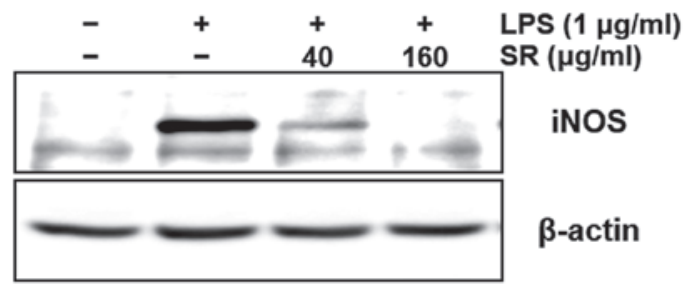

Figure 4. Anti-inflammatory effects of SR in LPS-induced RAW264.7 cells. Cells were incubated with LPS $(1 \mu \mathrm{g} / \mathrm{ml})$ with or without SR $(20,40,80$ and $160 \mu \mathrm{g} / \mathrm{ml}$ ) for $24 \mathrm{~h}$. (A) Nitrite accumulation was assessed as a measure of NO production. A group of LPS-induced cells was also treated with the NOS inhibitor NMMA $(50 \mu \mathrm{M})$. Values are presented as the mean \pm standard error of the mean of triplicate experiments. ${ }^{*} \mathrm{P}<0.05$ and ${ }^{* *} \mathrm{P}<0.01$ vs. LPS-only treated cells. (B) Protein expression levels of iNOS were examined using western blot analysis. $\beta$-actin was used as an internal control. SR, Scutellariae Radix; LPS, lipopolysaccharide; NO, nitric oxide; NOS, NO synthase; NMMA, $\mathrm{N}^{\mathrm{G}}$-Methyl-1-arginine acetate salt; iNOS, inducible NOS. 
murine macrophage cell line was evaluated using the CCK- 8 cell viability assay. RAW264.7 cells were exposed to various concentrations of SR $(20,40,80$ and $160 \mu \mathrm{g} / \mathrm{ml})$ for $24 \mathrm{~h}$. As shown in Fig. 3A, SR had no significant cytotoxic effects on RAW264.7 cells. Therefore, nontoxic concentrations of SR were used in all subsequent experiments.

Effects of SR on HO-1 expression. In order to examine the effects of SR on the protein expression of HO-1 in RAW264.7 cells, cells were treated with various concentrations of SR $(40,80$ and $160 \mu \mathrm{g} / \mathrm{ml})$ for $24 \mathrm{~h}$. Protein levels of HO-1 were then determined using western blot analysis. The results showed that SR promoted $\mathrm{HO}-1$ protein expression in a concentration-dependent manner (Fig. 3B).

Effects of SR on NO production and iNOS expression. RAW264.7 cells were treated with $1 \mu \mathrm{g} / \mathrm{ml} \mathrm{LPS} \mathrm{for} 24 \mathrm{~h}$ in the presence of SR $(20,40,80$ and $160 \mu \mathrm{g} / \mathrm{ml})$. The quantity of NO produced was determined by measuring the amount of nitrite converted from NO in the media. As shown in Fig. 4A, SR significantly suppressed LPS-induced NO release in a concentration-dependent manner compared with that LPS-treated cells without SR $(\mathrm{P}<0.05$ and 0.01$)$. In addition, NMMA, an inhibitor of NO synthase, markedly reduced NO release in RAW264.7 cells ( $\mathrm{P}<0.01)$ (Fig. 4A). The inhibitory effects of SR on NO release were $9.3,18.58,30.65$ and $47.22 \%$ at $20,40,80$ and $160 \mu \mathrm{g} / \mathrm{ml}$, respectively. Furthermore, it was investigated whether SR affects the protein expression of iNOS in RAW264.7 cells. As shown in Fig. 4B, iNOS protein expression was markedly increased in LPS-stimulated cells compared with that of the untreated control cells; however, this increase was attenuated by the addition of SR at 40 or $160 \mu \mathrm{g} / \mathrm{ml}$.

\section{Discussion}

Atherosclerosis comprises multiple events including LDL oxidation (21), inflammation at the injured area (22), foam cell formation (23) as well as VSMC proliferation and migration (24). Increasing evidence from in vitro and in vivo studies has suggested that oxidative modification of LDL, the major cholesterol carrier in the bloodstream, may be involved in the formation of early atherosclerotic lesions $(22,25,26)$. Atherosclerosis is widely accepted to be an inflammatory disease (27); therefore, therefore it was suggested that reducing the processes involved in LDL oxidation and the macrophage inflammatory response may be crucial for protecting against atherosclerosis. The current study investigated the effects of SR, extracts of the root of S. baicalensis, on LDL oxidation and LPS-induced inflammation.

The root of $S$. baicalensis is one of the primary ingredients in numerous traditional medicines in China, Japan and Korea (28-30). Studies have reported that traditional herbal formulas containing SR have anti-atherosclerotic activities (31-34). Ger-Gen-chyn-lian-tang was shown to reduce atherosclerotic progression in an apolipoprotein $\mathrm{E}^{-/-}$mouse model (31); in addition, Dahuang Zhechong, in pill form, inhibited VSMC proliferation and reversed the pathological changes observed in the aorta of atherosclerotic rabbit models $(32,33)$. Furthermore, Huanglian-jie-du-tang was demonstrated to inhibit the progression of atherosclerosis in diet-induced hypercholesterolemic rabbits (34).

The LDL oxidation hypothesis of atherosclerosis development suggested that inhibition of LDL oxidation may be a potential target for anti-atherosclerotic therapy (25). Previous studies have reported that SR inhibited lipid peroxidation in the rat liver $(35,36)$. In the present study, TBARS and REM assays were used to demonstrate that SR reduced LDL oxidation in a dose-dependent manner. Lipid hydroperoxides formation in LDL was previously reported to be an early event in LDL oxidation (37). In the present study, it was observed that SR decreased TBARS formation in $\mathrm{Cu}^{2+}$-induced oxLDL. In the REM assay, oxLDL migrated further compared with native LDL due to the increase in negative change; in addition, oxLDL was less visible following Coomassie blue staining due to partial degradation. In addition, SR inhibited $\mathrm{Cu}^{2+}$-induced LDL oxidation in a dose-dependent manner. These data suggested that SR possesses potent antioxidative abilities, which may be mediated through the inhibition of LDL oxidation.

In order to evaluate the anti-inflammatory effects of SR, a LPS-induced NO production model was used in the present study. iNOS expression and NO production were previously reported to be increased in atherosclerotic lesions (38). In the present study, nitrite concentrations in the culture medium were determined and the results indicated that SR significantly inhibited NO production in a concentration-dependent manner. In addition, western blot analysis revealed that SR treatment markedly inhibited iNOS expression. A previous study reported comparable anti-inflammatory effects of SR (9). Kim et al (9) reported that SR displayed significant anti-inflammatory effects in vitro and in vivo via suppression of mitogen-activated protein kinase signaling. The induction of HO-1 has been widely reported to be involved in the atherosclerosis process (39-41); therefore, it is regarded as a major therapeutic target for the prevention or treatment of atherosclerosis (40). The results of the current study demonstrated that SR induced HO-1 expression and exhibited anti-inflammatory properties. In addition, these results suggested that the induction of HO-1 contributed to the anti-inflammatory effects of SR and that SR may have potential therapeutic value in the treatment or prevention of atherosclerosis.

In conclusion, the results of the present study demonstrated that SR was able to reduce the oxidation of LDL and suppress the macrophage inflammatory response. The antioxidant properties and inhibitory effects of SR on macrophage inflammatory responses suggested that SR may be effective in the prevention or treatment of atherosclerosis; however, further studies are required in order to confirm these results.

\section{Acknowledgements}

The present study was supported by grants from the Korean Institute of Oriental Medicine (nos. K13030 and K12271).

\section{References}

1. Singh RB, Mengi SA, Xu YJ, et al: Pathogenesis of atherosclerosis: A multifactorial process. Exp Clin Cardiol 7: 40-53, 2002.

2. Ross R: The pathogenesis of atherosclerosis: a perspective for the 1990s. Nature 362: 801-809, 1993. 
3. Ross R: Atherosclerosis is an inflammatory disease. Am Heart J 138 (5 Pt 2): S419-S420, 1999.

4. Tong L, Wan M, Zhang L, et al: Simultaneous determination of baicalin, wogonoside, baicalein, wogonin, oroxylin A and chrysin of Radix scutellariae extract in rat plasma by liquid chromatography tandem mass spectrometry. J Pharm Biomed Anal 70: 6-12, 2012.

5. Gao Z, Huang $\mathrm{K}$, Yang $\mathrm{X}$ and $\mathrm{Xu} \mathrm{H}$ : Free radical scavenging and antioxidant activities of flavonoids extracted from the radix of Scutellaria baicalensis Georgi. Biochim Biophys Acta 1472: 643-650, 1999.

6. Park KI, Park HS, Kang SR, et al: Korean Scutellaria baicalensis water extract inhibits cell cycle G1/S transition by suppressing cyclin D1 expression and matrix-metalloproteinase-2 activity in human lung cancer cells. J Ethnopharmacol 133: 634-641, 2011.

7. Kumagai T,Müller CI,Desmond JC, et al: Scutellaria baicalensis, a herbal medicine: anti-proliferative and apoptotic activity against acute lymphocytic leukemia, lymphoma and myeloma cell lines. Leuk Res 31: 523-530, 2007.

8. Jung HS, Kim MH, Gwak NG, et al: Antiallergic effects of Scutellaria baicalensis on inflammation in vivo and in vitro. J Ethnopharmacol 141: 345-349, 2012

9. Kim EH, Shim B, Kang S, et al: Anti-inflammatory effects of Scutellaria baicalensis extract via suppression of immune modulators and MAP kinase signaling molecules. J Ethnopharmacol 126: 320-331, 2009.

10. Maines MD: The heme oxygenase system: a regulator of second messenger gases. Annu Rev Pharmacol Toxicol 37: 517-554, 1997.

11. Origassa CS and Câmara NO: Cytoprotective role of heme oxygenase-1 and heme degradation derived end products in liver injury. World J Hepatol 5: 541-549, 2013.

12. Jansen $T$ and Daiber A: Direct antioxidant properties of bilirubin and biliverdin. Is there a role for biliverdin reductase? Front Pharmacol 3: 30, 2012.

13. Otterbein LE, Kolls JK, Mantell LL, et al: Exogenous administration of heme oxygenase-1 by gene transfer provides protection against hyperoxia-induced lung injury. J Clin Invest 103 1047-1054, 1999

14. Ryter SW, Alam J and Choi AM: Heme oxygenase-1/carbon monoxide: from basic science to therapeutic applications. Physio Rev 86: 583-650, 2006.

15. Re R, Pellegrini N, Proteggente A, et al: Antioxidant activity applying an improved ABTS radical cation decolorization assay. Free Radic Biol Med 26: 1231-1237, 1999.

16. Moreno MI,Isla MI, Sampietro AR and Vattuone MA: Comparison of the free radical-scavenging activity of propolis from several regions of Argentina. J Ethnopharmacol 71: 109-114, 2000.

17. Barnhart RL, Busch SJ and Jackson RL: Concentration-dependent antioxidant activity of probucol in low density lipoproteins in vitro: probucol degradation precedes lipoprotein oxidation. J Lipid Res 30: 1703-1710, 1989.

18. Buege JA and Aust SD: Microsomal lipid peroxidation. Methods Enzymol 52: 302-310, 1978.

19. Sparks DL and Phillips MC: Quantitative measurement of lipoprotein surface charge by agarose gel electrophoresis. J Lipid Res 33: 123-130, 1992.

20. Wallin B, Rosengren B, Shertzer HG and Camejo G: Lipoprotein oxidation and measurement of thiobarbituric acid reacting substances formation in a single microtiter plate: its use for evaluation of antioxidants. Anal Biochem 208: 10-15, 1993

21. Chisolm GM and Steinberg D: The oxidative modification hypothesis of atherogenesis: an overview. Free Radic Biol Med 28: $1815-1826,2000$.
22. Charo IF and Taub R: Anti-inflammatory therapeutics for the treatment of atherosclerosis. Nat Rev Drug Discov 10: 365-376, 2011

23. Li AC and Glass CK: The macrophage foam cell as a target for therapeutic intervention. Nat Med 8: 1235-1242, 2002.

24. Andrés V: Control of vascular cell proliferation and migration by cyclin-dependent kinase signalling: new perspectives and therapeutic potential. Cardiovasc Res 63: 11-21, 2004.

25. Heinecke JW: Lipoprotein oxidation in cardiovascular disease: Chief culprit or innocent bystander? J Exp Med 203: 813-816, 2006.

26. Norata GD, Tonti L, Roma P and Catapano AL: Apoptosis and proliferation of endothelial cells in early atherosclerotic lesions: Possible role of oxidised LDL. Nutr Metab Cardiovasc Dis 12 297-305, 2002.

27. Libby P, Ridker PM and Maseri A: Inflammation and atherosclerosis. Circulation 105: 1135-1143, 2002.

28. Li C, Zhou L, Lin G and Zuo Z: Contents of major bioactive flavones in proprietary traditional Chinese medicine products and reference herb of Radix Scutellariae. J Pharm Biomed Anal 50(3):298-306, 2009.

29. Akagiri S, Naito Y, Ichikawa H, et al: Bofutsushosan, an Oriental herbal medicine, attenuates the weight gain of white adipose tissue and the increased size of adipocytes associated with the increase in their Expression ef uncoupling protein 1 in high-fat diet-fed male KK/Ta mice. J Clin Biochem Nutr 42: 158-166, 2008.

30. Tanaka K, Nara K, Nishimura T, et al: Fever of unknown origin successfully treated by oren-gedoku-to (huanglian-jie-du-tang). Int J Gen Med 6: 829-832, 2013.

31. Ho FM, Liao YH, Yang AJ, et al: Anti-atherosclerotic action of Ger-Gen-Chyn-Lian-Tang and AMPK-dependent lipid lowering effect in hepatocytes. J Ethnopharmacol 142: 175-187, 2012

32. Ji YY, Liu JT, Wang ZD, et al: Study on anti-atherosclerotic mechanisms of divided functional recipes of dahuang zhechong pill in rabbits. China J Chin Mater Med 32: 1077-1081, 2007 (In Chinese).

33. Ji YY, Liu JT and Li JL: Effect of the disassembled recipes of dahuang zhechong pill on proliferation and apoptosis of vascular smooth muscle cells in atherosclerotic rabbits. Chin J Integr Tradit West Med 26: 913-917, 2006 (In Chinese).

34. Sekiya N, Kainuma M, Hikiami H, et al: Oren-gedoku-to and Keishi-bukuryo-gan-ryo inhibit the progression of atherosclerosis in diet-induced hypercholesterolemic rabbits. Biol Pharm Bull 28: 294-298, 2005.

35. Kimura Y,Kubo M, Kusaka K, et al: Studies on Scutellariae radix. V. Effects on ethanol-induced hyperlipemia and lipolysis in isolated fat cells. Chem Pharm Bull (Tokyo) 30: 219-222, 1982.

36. Kimura Y, Okuda H, Taira Z, et al: Studies on Scutellariae radix. IX. New component inhibiting lipid peroxidation in rat liver. Planta Med 50: 290-295, 1984

37. Girotti AW: Lipid hydroperoxide generation, turnover and effector action in biological systems. J Lipid Res 39: 1529-1542, 1998.

38. Napoli C and Ignarro LJ: Nitric oxide and atherosclerosis. Nitric Oxide 5: 88-97, 2001.

39. Morita T: Heme oxygenase and atherosclerosis. Arterioscler Thromb Vasc Biol 25: 1786-1795, 2005.

40. Liu D, He Z, Wu L and Fang Y: Effects of induction/inhibition of endogenous heme oxygenase-1 on lipid metabolism, endothelial function and atherosclerosis in rabbits on a high fat diet. J Pharmacol Sci 118: 14-24, 2012.

41. Wu ML, Ho YC, Lin CY and Yet SF: Heme oxygenase-1 in inflammation and cardiovascular disease. Am J Cardiovasc Dis 1: 150-158, 2011. 